\title{
O PROCESSO DE ESCOLARIZAÇÃO DAS TRAVESTIS E DAS MULHERES TRANS NO BRASIL
}

\section{ENSAIO TEÓRICO}

GOMES FILHO, Teodoro Antunes ${ }^{1}$

GOMES FILHO, Teodoro Antunes. O processo de escolarização das travestis e das mulheres trans no Brasil. Revista Científica Multidisciplinar Núcleo do Conhecimento. Ano 05, Ed. 10, Vol. 21, pp. 111-118. Outubro de 2020. ISSN: 24480959, Link de acesso: https://www.nucleodoconhecimento.com.br/educacao/mulheres-trans

\section{RESUMO}

O presente ensaio teórico tenta trazer à luz a problemática do processo de escolarização das travestis e das mulheres trans no Brasil. Tem por objetivos abordar seu grau de escolarização, compreender suas trajetórias na passagem pela educação formal, identificar os motivos que as levam a permanecer ou evadir das instituições, identificar se sofrem violência física ou simbólica, verificar se consideram garantido o que diz o artigo 205 da CF, e verificar se a educação formal contribui para o enfrentamento da precarização da vida. A metodologia utilizada para a elaboração deste ensaio teórico foi um levantamento bibliográfico.

Palavras-chave: escolarização, travestis/mulheres trans, violência física/simbólica.

\section{INTRODUÇÃO}

De acordo com o IBGE, a expectativa média de vida da população brasileira em 2017 era de 74,6 anos e, segundo a Associação Nacional de Transexuais e Travestis

1 Licenciado em Geografia (UFPEL), Licenciado em Pedagogia (UNICESUMAR), Analista e Desenvolvedor de Sistemas (UNOPAR), Especialista em Educação (UFSM) e Mestre em Educação (UNISINOS). 
(ANTRA), a expectativa média de vida de pessoas trans no Brasil não passava dos 35 anos de idade. A partir destes dados passei a me interessar pelo assunto, e meu interesse aumentou após ter lido o livro Travestis Envelhecem? do psicólogo Pedro Paulo Sammarco Antunes, publicado em 2013 como resultado de sua dissertação de mestrado (2008 - 2010) pela PUC-SP. Antunes identificou que, por serem consideradas desviantes e anormais, travestis são vistas como não humanas desde tenra idade, atravessam a vida como invisíveis e sob muito preconceito, improvisam suas existências em contextos violentos, têm expectativas de vida baixas, e as que vivem até a chamada velhice podem ser consideradas verdadeiras sobreviventes $\mathrm{e}$ acabam servindo de referência e exemplo para as mais jovens. A pesquisa de Antunes resultou no levantamento de demandas e necessidades em relação às travestis e demonstrou que precisam urgentemente de políticas públicas que as reconheçam como humanas desde sempre, para que dessa forma possam chegar à velhice com dignidade e respeito, tendo assegurados os direitos humanos universais. Para sua pesquisa Antunes entrevistou três travestis, sendo uma em Salvador (BA) e duas em São Paulo (SP).

O interesse pela temática consolidou-se com a leitura do livro Travestis na Escola, de Luma Nogueira de Andrade, primeira travesti do Brasil doutora e professora do Ensino Superior. O livro de Andrade, publicado em 2015, é fruto de sua pesquisa de doutorado (2008 - 2012) pela UFC e teve como objetivo desvendar as resistências e assujeitamentos das jovens travestis na escola. Aborda o uso das táticas que as jovens estudantes travestis fazem para burlar a disciplina e o controle, e produzir linhas de fuga para o acesso e a permanência no espaço escolar. A pesquisa de Andrade foi realizada no estado do Ceará, teve caráter etnográfico e apontou que dos 184 municípios apenas 25 possuíam jovens transgêneros matriculados em escolas estaduais. Em sua pesquisa, Andrade observou que a pressão sofrida pelas travestis pesquisadas foi tão intensa que as obrigou a abandonar os estudos, sendo disseminada a ideia de que foi por escolha própria. Para Andrade esta justificativa tenta mascarar o fracasso da escola em lidar com as diferenças, camuflando o processo de evasão involuntária induzida pela instituição. Em sua pesquisa Andrade entrevistou três travestis em municípios do interior do estado do Ceará. 


\section{FOUCAULT E AS RELAÇÕES DE GÊNERO}

Para a elaboração deste ensaio teórico foram analisadas publicações dos pesquisadores Jane Felipe, Guacira Louro, Fernando Seffner e Dagmar Meyer. Para suas análises sobre a temática educação, sexualidade e relações de gênero estes quatro pesquisadores, bem como Pedro Paulo Sammarco Antunes e Luma Nogueira de Andrade utilizaram-se do aporte teórico de Michel Foucault, dentre outros estudiosos no assunto. Portanto, o meu olhar inicial neste ensaio teórico procura levantar algumas das principais contribuições de Foucault sobre esta temática.

Segundo Felipe (2006, p. 257):

As análises advindas das contribuições de Michel Foucault (1989, 1992, 1993) sobre o uso do corpo e seus prazeres ao longo da história, as relações de poder-saber e o governo dos corpos, podem ser muito produtivas para se pensar alguns temas ligados à sexualidade, bem como perceber e analisar como os sujeitos têm sido posicionados pelos diferentes discursos - médico, psicológico, jurídico, religioso e educacional.

Nesse sentido, o panoptismo possibilita a análise de como se estrutura o processo da disciplina, hierarquia e dominação em diferentes espaços, que é consequentemente reproduzido no âmbito escolar. As microrrelações de poder, as técnicas de vigiar e punir e toda a estrutura de controle, classificação, normatização e higienização introduzidas na escola, tiveram o intuito de formar o indivíduo obediente ao enquadramento, semelhante ao das prisões, indústrias, corporações militares e hospitais.

Para representar as manifestações de um poder maior (que tudo vê e sabe) Foucault desenvolveu um conceito chamado panóptico. O panóptico é uma estrutura complexa (que permite ao observador ver sem ser visto), mas o cerne da questão é o conceito de vigilância e acima de tudo o poder que ela exerce. Este conceito está disponível na obra de Foucault intitulada Vigiar e Punir: nascimento da prisão.

Para Louro (1999, p. 06): 
A sexualidade, afirma Foucault (1988), é um "dispositivo histórico". Em outras palavras, ela é uma invenção social, uma vez que se constitui, historicamente, a partir de múltiplos discursos sobre o sexo: discursos que regulam, que normatizam, que instauram saberes, que produzem "verdades".

Como ferramenta analítica, o conceito de dispositivo é desenvolvido por Foucault em sua obra História da Sexualidade: a vontade de saber. Contudo, o autor (2000, p. 244) explicita tal conceito como:

Um conjunto decididamente heterogêneo que engloba discursos, instituições, organizações arquitetônicas, decisões regulamentares, leis, medidas administrativas, enunciados científicos, proposições filosóficas, morais, filantrópicas. Em suma, o dito e o não dito são os elementos do dispositivo. O dispositivo é a rede que se pode tecer entre estes elementos.

Nesse sentido, evidencia-se que os documentos normativos determinam que tipo de homem e mulher devemos ser, atendendo ao que é conveniente para a maioria consultada, mas em nome dessa conveniência se anulam outras possibilidades de existência, se nega a existência de uns para manter a hegemonia de outros.

Com base na Constituição Federal de 1988, o princípio da igualdade deve ser garantido na escola a todos os estudantes, não sendo permitida qualquer restrição em relação às diferenças seja de que natureza for. Portanto, fica assegurado o direito ao acesso e à permanência do estudante na escola. Conforme artigo 205 da CF:

a educação, direito de todos e dever do Estado e da família, será promovida e incentivada com a colaboração da sociedade, visando ao pleno desenvolvimento da pessoa, seu preparo para o exercício da cidadania e sua qualificação para o trabalho.

Já o artigo 206 diz que "o ensino será ministrado com base no princípio da igualdade de condições para o acesso e permanência na escola".

Para Seffner (2014, p. 69):

A importância atribuída ao "problema sexual" parte da ênfase no binarismo, que tem sua origem entre os gregos e os judeus (FOUCAULT, 1980). O binarismo é um elemento cultural forte em nosso meio, e ele 
ajuda a explicar a importância e o modo como lidamos com a sexualidade. Definidos alguns pólos binários (homem e mulher, ativo e passivo, heterossexual e homossexual, branco e negro, rico e pobre, jovem e velho, ocidental e oriental), de imediato valorizamos um dos polos, em detrimento do outro, que é visto como inferior ou uma versão degradada do primeiro. O caráter holístico que a sexualidade tem em nossa sociedade explica em parte nossa preocupação com ela, pois sexo literalmente "tem a ver com tudo" hoje em dia.

A concepção de uma identidade sexual binária, onde cada qual deve se acomodar do lado dos homens ou das mulheres, segundo o sexo biológico, foi especialmente nos últimos anos fortemente colocada em questão, uma vez que a identidade sexual de um indivíduo pode mudar no curso de sua vida e os transexuais ou transgêneros são exemplos de tal modificação.

Meyer (2008, p. 65) nos auxilia com as ideias do filósofo ao dizer que as micropenalidades:

São instrumentos pedagógicos e disciplinadores que podem ser mais ou menos sutis, mas são sempre processos punitivos que se propõem a eliminar esses comportamentos indesejáveis. Estou falando, de certa forma, dos mecanismos de interdição (FOUCAULT, 1988), que ensinam que não se pode falar de tudo, nem em qualquer lugar, e que só algumas pessoas podem abordar determinados temas. Isso fica bastante claro no ambiente escolar, em que o tema sexualidade é visto como do domínio da professora de ciências (de biologia, mais especificamente) ou do professor de educação física e deve ser abordado por meio de linguagem científica.

Nesse sentido podemos entender que o poder provém de todas as partes, em cada relação entre um ponto e outro. $E$ tais relações são dinâmicas, móveis e mantêm e destroem grandes esquemas de dominação. Como em todas as sociedades, as hierarquias sexuais e as noções de gênero se relacionam intimamente com as hierarquias de poder na sociedade e na escola, mesmo presentes de forma subjetiva.

Somado às contribuições de Foucault trazidas anteriormente pelos quatro pesquisadores, evidencia-se que a problemática da violência física ou simbólica que sofre a população LGBT acaba por refletir na escolarização das travestis e mulheres trans durante seu percurso pela educação formal. 


\section{A PRECARIZAÇÃO DA VIDA}

Butler (2011 e 2019) nos apresenta o conceito de vidas precárias, isto é, uma compreensão de que o vínculo entre as vidas humanas é atravessado por condições de desigualdade e pela capacidade de reconhecimento da humanidade do outro. Dessa forma, apenas atendemos e reagimos com alteridade e afeto quando construímos uma imagem representacional ou enquadramento de igualdade com o outro. Nas palavras de Butler, (2015, p. 40) "afirmar que a vida é precária é afirmar que a possibilidade de sua manutenção depende, fundamentalmente, das condições sociais e políticas, e não somente de um impulso interno para viver".

A escola é um dos principais desencadeadores desses processos de exclusão, expressos por uma violência anunciada, em sua maioria, por parte do corpo discente e outra violência velada ou silenciada, pelos agentes escolares. Cabe ainda destacar que essas formas de violência, principalmente a anunciada, muitas vezes se consagra em outra forma de violência que definimos como violência materializada, incidindo diretamente na possibilidade de prejuízo e/ou violação física sobre a pessoa exposta (FRANCO, 2015).

Bohm, em sua dissertação de mestrado (2007 - 2009), intitulada Os "Monstros" e a Escola: identidade e escolaridade de sujeitos travestis, realizou pesquisa sobre a escolarização das travestis da cidade de Porto Alegre (RS) e região metropolitana e destaca que a identidade travesti:

representa um desafio perturbador à organização e aos princípios heteronormativos que habitam também a escola. Poucos ou raros são os casos de ingresso, resistência e permanência escolar desses sujeitos, uma vez que a relação das travestis com os demais colegas é marcada pelo exercício do bullying e, com seus professores e gestores, é permeada por muitos problemas: a recusa de ter o nome social aceito na chamada, por exemplo, e a proibição de poder usar roupas ou acessórios femininos, dentre outros (BOHM, 2009, p. 81).

Pessoas que expressam identidades de gênero fora da norma binária instituída têm dificuldades nas mais variadas esferas da vida cotidiana e pragmática, sendo os embaraços e violências perpassados os mais variados possíveis, como a dificuldade 
de inserção no mercado de trabalho formal. Na instituição escolar são comuns relatos de dificuldade de utilização do nome social nas folhas de frequência, do uso de uniforme adequado ao gênero (e não ao sexo biológico), bem como a utilização de sanitários (NATAL-NETO, 2016).

Para concluir este ensaio teórico referente às travestis/mulheres trans e sua relação com educação formal, trago algumas considerações da dissertação de mestrado (2011 - 2013) Reidel, intitulada A Pedagogia do Salto Alto: história de professoras transexuais e travestis na educação brasileira. No estudo quanti-qualitativo com cerca 40 professoras transexuais e travestis de diversos estados do Brasil, especialmente do Rio Grande do Sul, Reidel (2013, p. 53) pode observar que:

Quando vejo professoras trans dentro das escolas ou lugares marcados por um tipo de aprendizagem, reconheço que aquele lugar tem um olhar sensível às questões de gênero e de respeito. Entendo que o lugar ocupado por aquela professora tem um significado positivo no aspecto social e cultural e, se ela permaneceu neste espaço, é porque a própria escola ressignificou seu plano político e pedagógico de atuação. Se a professora transexual ou travesti venceu o preconceito e não se intimidou diante da sua condição de vida, demonstrando segurança e exigindo seus direitos, conquistou os grupos e manteve seu status.

Devido a não aceitação de sua sexualidade e gênero, por muito tempo travestis e transexuais ficaram de fora da escola. A busca por uma formação igualitária, pelo conhecimento para desenvolver competências e habilidades, faz com que haja resistência por parte desse grupo social para que tenham um lugar no mercado de trabalho formal.

\section{CONSIDERAÇÕES FINAIS}

Para a UNESCO a eliminação das desigualdades de gênero é determinante para a construção de uma sociedade inclusiva e equitativa, pois todos os estudantes têm o direito de viver e aprender em um ambiente livre de discriminação e violência.

Por tudo isso, faz-se necessário ações que efetivamente tornem a escola um espaço de todos, sejam estes de diferentes classes sociais, credos religiosos, gêneros 
sexuais, ou outros. Os projetos pedagógicos precisam estabelecer uma educação pautada na empatia, igualdade e humanidade, pois somente desta forma se conseguirá construir uma sociedade mais justa. Além disso, as instituições de ensino formal precisam compreender o gênero como uma construção social, cultural, política e histórica (VASCONCELOS, 2018).

\section{REFERÊNCIAS}

ANDRADE, Luma Nogueira de. Travestis na escola: assujeitamento e resistência à ordem normativa. Rio de Janeiro: Metanoia, 2015.

ANTRA. Associação Nacional de Travestis e Transexuais. Disponível em https://antrabrasil.org/. Acesso em 14/08/2020.

ANTUNES, Pedro Paulo Sammarco. Travestis envelhecem? São Paulo: Annablume, 2013.

BOHM, Alessandra Maria. Os "monstros" e a escola: identidade e escolaridade de sujeitos travestis. Dissertação de Mestrado. Porto Alegre: UFRGS, 2009. Disponível em https://lume.ufrgs.br/handle/10183/29931. Acesso em 07/12/2019.

BRASIL. Constituição Federal de 1988. Disponível em http://www.planalto.gov.br/ccivil_03/constituicao/constituicao.htm. Acesso em 14/08/2020.

BUTLER, Judith. Quadros de Guerra - quando a vida é passível de luto? São Paulo: Civilização Brasileira, 2015.

BUTLER, Judith. Vida precária. Contemporânea - Revista de Sociologia da UFSCar. São Carlos, Departamento e Programa de Pós-Graduação em Sociologia da UFSCar, 2011, n.1, p. 13-33.

BUTLER, Judith. Vida precária: os poderes do luto e da violência. Belo Horizonte: Autêntica, 2019. 
FELIPE, Jane. Representações de gênero, sexualidade e corpo na mídia. Revista Tecnologia e Sociedade, 2006. Disponível em: https://periodicos.utfpr.edu.br/rts/article/view/2490. Acesso em 07/12/2019.

FOUCAULT, Michel. História da sexualidade 1. A vontade de saber. Rio de Janeiro: Paz e Terra, 2019.

FOUCAULT, Michel. Microfísica do poder. Rio de Janeiro: Graal, 2000.

FOUCAULT, Michel. Vigiar e punir: o nascimento da prisão. Petrópolis: Vozes, 2014.

IBGE. Instituto Brasileiro de Geografia e Estatística. Disponível em https://www.ibge.gov.br/. Acesso em 14/08/2020.

LOURO, Guacira Lopes (Org.). O corpo educado: Pedagogias da Sexualidade. Belo Horizonte: Autêntica, 2000.

MEYER, Dagmar. Limites e possibilidades de uma ação educativa na redução da vulnerabilidade à violência e à homofobia. Ensaio: aval. pol. públ. educ. [online]. 2008, vol.16, n.58, pp.59-76. ISSN 1809-4465. Disponível em: https://www.scielo.br/scielo.php?pid=s010440362008000100005\&script=sci_abstract\&tIng=pt. Acesso em 07/12/2019.

NATAL-NETO, Flávio de Oliveira; MACEDO, Geovani da Silva; BICALHO, Pedro Paulo Gastalho. A Criminalização das Identidades Trans na Escola: Efeitos e Resistências no Espaço Escolar. Psicol. Ensino \& Form., São Paulo, v. 7, n. 1, p. 78-86, 2016 Disponível

em

http://pepsic.bvsalud.org/scielo.php?script=sci_arttext\&pid=S2177-

$20612016000100008 \& \operatorname{lng}=$ pt\&nrm=iso.

Acesso

em 25 set. 2020. http://dx.doi.org/10.21826/2179-58002016717886.

REIDEL, Marina. A pedagogia do Salto Alto: histórias de professoras transexuais e travestis na educação brasileira. Dissertação de mestrado. Porto Alegre: UFRGS, 
2013.

em:

https://www.lume.ufrgs.br/bitstream/handle/10183/98604/000922589.pdf?sequence= 1. Acesso em 07/12/2019.

SEFFNER, Fernando. Sexualidade: isso é mesmo matéria escolar? Revista Teoria e Prática da Educação, 2014. Disponível em: http://periodicos.uem.br/ojs/index.php/TeorPratEduc/article/view/27750. Acesso em 07/12/2019.

UNESCO. Disponível em https://nacoesunidas.org/agencia/unesco/. Acesso em 07/12/2019.

VASCONCELOS, Fábio R S. Evasão Escolar de alunas travestis e transexuais. In: Seminário Corpo, Gênero e Sexualidade. Rio Grande: FURG, 2018. Disponível em https://seminariocorpogenerosexualidade.furg.br/images/arquivo/250.pdf. Acesso em 07/12/2019.

Enviado: Setembro, 2020.

Aprovado: Outubro, 2020. 